\title{
Estratégia\&Negócios
}

ISSN 1984-3372

http://www.portaldeperiodicos.unisul.br/index.php/EeN/

\section{ANÁLISE DO PAPEL DA INCUBADORA NA INTERNACIONALIZAÇÃO DE EMPRESAS DE BASE TECNOLÓGICA, INCUBADAS E GRADUADAS}

\section{ANALYSIS OF THE ROLE OF BUSINESS INCUBATOR IN INTERNATIONALIZATION OF BASIC TECHNOLOGY COMPANIES}

\section{Gabriela Gonçalves Silveira Fiates}

Professora/ Pesquisadora pela Universidade Federal de Santa Catarina - UFSC - Departamento de Administração - CSE. E-mail: gabriela.fiates@ufsc.br

\section{Cristina Martins}

Doutoranda em Administração pela Universidade Federal de Santa Catarina - UFSC.

E-mail: crismartins2611@gmail.com

\section{José Eduardo Azevedo Fiates}

Mestre em Engenharia de Produção e Sistemas pela Universidade Federal de Santa Catarina - UFSC. Diretor Executivo do Parque de Inovação Sapiens Parque. Diretor de Inovação da Fundação CERTI, e Diretor Geral da CVentures.

E-mail: jef@certi.org.br

\section{Graciella Martignago}

Doutoranda em Administração pela Universidade Federal de Santa Catarina - UFSC.

E-mail: graci.floripa@gmail.com

\section{Neri dos Santos}

Professor do Programa de Pós-Graduação em Engenharia e Gestão do Conhecimento Centro Tecnológico - CTC Universidade Federal de Santa Catarina - UFSC.

E-mail: neri@egc.ufsc.br

Recebido em 07/10/2012. Aprovado em 12/04/2013. Disponibilizado em 05/05/2013.

Avaliado pelo Sistema double blind review

R. eletr. estrat. neg., Florianópolis, v.6, n.1, p. 252-274, jan./abr. 2013

http://portaldeperiodicos.unisul.br/index.php/EeN/index
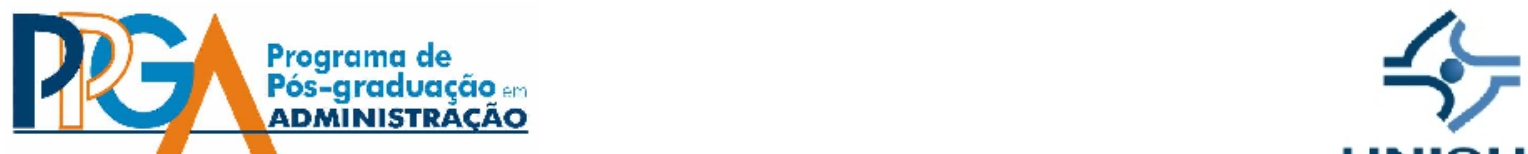

UNISUL

CCopyright 2008 UNISUL-PPGA/Estratégia e Negócios. Todos os direitos reservados. Permitida citação parcial, desde que identificada a fonte. Proibida a reprodução total. Em caso de dúvidas, consulte o editor:

ademar.unisul@gmail.com; (48) 3229-19 


\section{RESUMO}

As transformações econômicas e tecnológicas ocorridas a partir da segunda metade do século XX ampliaram os mercados, reduziram os limites impostos pelas fronteiras dos países e promoveram de forma real e inequívoca a globalização das operações comerciais, sobretudo para os países emergentes. Neste contexto, o Brasil mostra-se como importante player, juntamente com os demais países que compõem o BRICS - Brasil, Rússia, Índia, China e África do Sul, grupo com poder político em expansão, dada a relevância de seus mercados. Apesar disto, a participação brasileira no comércio global ainda é pequena, quando comparada a outros países igualmente emergentes. O nível de internacionalização é particularmente mais baixo para produtos de maior valor agregado, como a inovação tecnológica. A maioria dos produtos exportados pelo Brasil em 2011 (65,8\%) é composta por produtos de baixa e média-baixa tecnologia, $27,9 \%$ é de média-alta tecnologia e somente $6,2 \%$ é de alta tecnologia (MDIC, 2012). Nesse sentido, este artigo visa analisar as características do processo de internacionalização de pequenas e médias empresas de base tecnológica, incubadas e graduadas buscando identificar o papel das incubadoras nesse processo. Partiu-se de três premissas básicas: que as empresas de base tecnológica são essencialmente inovadoras; que as incubadoras de empresas se constituem em ambientes potencializadores de redes de relacionamento, tanto entre as empresas incubadas e graduadas, como com agentes externos. E, finalmente, a terceira premissa é que a inovação é uma vantagem competitiva que alavanca o processo de internacionalização de empresas e mostra-se fundamental para o desempenho competitivo da empresa no mercado externo. A pesquisa a partir de casos de pequenas empresas de base tecnológica mostra-se relevante dada a necessidade do Brasil de estimular a inserção externa de empresas que comercializam produtos intensivos em tecnologia. A pesquisa é de caráter descritivo, na forma de um estudo multicaso com seis empresas, três incubadas e três graduadas. Os resultados apontam que a inovação configura-se realmente como a principal vantagem para a competição em mercados internacionais. De forma intencional e planejada, há uma aceleração do processo de internacionalização nas empresas mais jovens, já concebidas com uma visão global. Constatou-se que a incubadora favorece a formação de redes de relacionamento que estimulam a inovação e a interação com outros atores que podem 
fomentar o processo de internacionalização, no entanto, não há ações percebidas pelos empresários próprias para esta finalidade, o que aponta para uma oportunidade de ação sistemática das incubadoras no apoio à internacionalização de empresas.

Palavras-chave: Internacionalização. Incubadoras. Inovação. Base-tecnológica.

\section{INTRODUÇÃO}

As transformações ocorridas a partir do século XX derrubaram barreiras comerciais e ampliaram os mercados promovendo de forma real a globalização das operações comerciais. Nesse contexto, os países emergentes, que participam com uma menor parte do comércio internacional e dos investimentos externos diretos, em relação às economias avançadas, estão tendo a oportunidade de aumentar sua participação. Diante disso, o Brasil apresenta-se como um importante player, juntamente com os demais países que compõem o BRICS - Rússia, Índia, China e África do Sul, grupo com poder político em expansão devido à relevância de seus mercados. O Brasil tem apresentado relevante desempenho exportador, principalmente de produtos básicos como grãos e metais.

Em 2011, o Brasil registrou comércio recorde de US\$ 482,3 bilhões, com ampliação de $25,7 \%$ sobre 2010 . Na comparação com 2010, as vendas de produtos básicos cresceram $36,1 \%$, enquanto de semimanufaturados e manufaturados ampliaram em, respectivamente, $27,7 \%$ e $16,0 \%$. O grupo de produtos industrializados respondeu por metade do total exportado pelo Brasil no ano de 2011 (MDIC, 2012).

Apesar disto, a participação brasileira no comércio global ainda é pequena, quando comparada a outros países igualmente emergentes. O Brasil ocupa a $22^{a}$ posição no ranking dos países exportadores, respondendo por somente 1,3\% das exportações mundiais. A China, primeiro lugar no ranking mundial de exportadores, responde por $10,4 \%$ do total exportado pelo mundo. A Coréia do Sul, país igualmente pouco desenvolvido na década de sessenta e geralmente utilizado como referência por autores brasileiros para processos de desenvolvimento econômico (SUZIGAN; FURTADO, 2010), é o sétimo país exportador respondendo por 3,1\% da exportação mundial. A Rússia participa com 2,6\% da exportação 
mundial ocupando a $12^{-a}$ posição. E, mesmo a Índia, país com uma renda per capita inferior à brasileira, exporta mais que o Brasil, respondendo por 1,4\% das exportações mundiais (MDIC, 2002).

Ao analisar o comércio de produtos de maior valor agregado, com inovação tecnológica, o nível de internacionalização é ainda mais baixo. Dados da balança comercial de 2011 , considerando os produtos por fator agregado, mostram que $47,8 \%$ das exportações foram realizadas por produtos básicos, $14,1 \%$ por semimanufaturados e somente $36,1 \%$ do total exportado foi de produtos manufaturados. A maioria dos produtos exportados pelo Brasil em 2011 (65,8\%) é composta por produtos de baixa e média-baixa tecnologia, 27,9\% é de média-alta tecnologia e somente $6,2 \%$ das exportações são de produtos de alta tecnologia (MDIC, 2012). Este fato chama a atenção já que a capacidade de inovação tem sido frequentemente apontada como fator de vantagem para o desenvolvimento econômico e para a internacionalização da firma (SCHUMPETER, 1934; LACHENMAIER; WOBMANN, 2004). Embora esta fosse uma preocupação ainda do governo de Fernando Henrique Cardoso, parece que as mudanças neste cenário tem sido muito mais lentas que a dinâmica mundial.

Nesse contexto, parece ser ainda mais difícil figurar no rol das exportadoras se a empresa for de pequeno ou médio porte, tomando-se como base a classificação do SEBRAE relativa ao número de pessoas, associando a micro empresa à faixa de 1 a 19 pessoas ocupadas, a pequena empresa à de 20 a 99 pessoas, a média empresa com 100 a 499 e grande empresa com 500 ou mais pessoas ocupadas. Veiga e Markwald (1997) verificaram que a participação das pequenas e médias empresas nas exportações brasileiras é pequena e intermitente, apesar de verificarem que um grande número destas firmas esteja anualmente presente na base exportadora do país. Os autores concluem que há uma diferença significativa na participação das exportações de acordo com o porte da empresa. Em 2011, $94,8 \%$ das exportações foram realizadas por grandes firmas, 4,1\% por médias, e cai para 1\%, quando é micro ou pequena (MDIC, 2012). Ao comparar com os dados divulgados por Markwald e Puga (2002), observa-se que, nos últimos dez anos, houve ainda maior concentração das exportações nas mãos das grandes empresas. 
Diante desse cenário e da importância das pequenas e médias empresas (PME's) para a economia, o governo brasileiro, tem se aliado a instituições de promoção das exportações para desenvolver e aplicar mecanismos de apoio visando fomentar a atuação internacional das empresas de pequeno e médio porte, promovendo-Ihes acesso a novos mercados em crescimento e inserção de novos produtos com maior valor agregado (COELHO; LARA, 2003).

Em consequência dessa realidade e da carência de estudos que avaliem a internacionalização de empresas de países emergentes e de grandes dimensões territoriais, como o Brasil (MAIS; CARVALHO; AMAL; HOFFMANN, 2010), esse artigo se propõe a analisar as características do processo de internacionalização de pequenas e médias empresas de base tecnológica, incubadas e graduadas buscando identificar o papel das incubadoras neste processo.

Parte-se de duas premissas que serão posteriormente sustentadas na próxima seção: a primeira é que a capacidade de inovação de uma empresa influencia em sua capacidade de internacionalização, uma vez que representa uma vantagem competitiva alavancadora do processo de internacionalização de empresas. A segunda é que as incubadoras de empresas se constituem em ambientes potencializadores de redes sociais tanto entre as empresas incubadas e graduadas como destas com agentes externos como Instituições de ensino e de pesquisa, agentes governamentais e de fomento entre outras, e estas redes são catalisadoras tanto do processo de inovação como de internacionalização.

O artigo está estruturado em mais quatro seções, além desta introdução, que apresentam respectivamente o referencial teórico, a metodologia do estudo, a apresentação e análise dos dados e as considerações finais.

\section{FUNDAMENTAÇÃO TEÓRICA}

A internacionalização de uma empresa consiste em sua participação ativa em mercados externos. Vários autores estudaram este fenômeno ao longo dos anos, e desenvolveram teorias tentando explicar o processo de internacionalização. Utilizando-se de 
uma abordagem diferenciada, cada um contribuiu para o melhor entendimento do tema, como mostra o quadro 1 , que sintetiza estas teorias e seus respectivos autores.

Quadro 1 - Resumo das Teorias de Internacionalização

\begin{tabular}{|c|c|c|c|}
\hline TEORIAS & AUTORES & CONTEÚDO & DESTAQUE \\
\hline $\begin{array}{l}\text { Escola Nórdica } \\
\text { de Negócios } \\
\text { Internacionais } \\
\text { (Uppsala } \\
\text { Suécia) }\end{array}$ & $\begin{array}{l}\text { Edith Penrose, } \\
\text { Richard Cyert, } \\
\text { James March, } \\
\text { Yair Aharoni } \\
\text { J. Johanson } \\
\text { J. E. Vahlne }\end{array}$ & $\begin{array}{l}\text { Estudos de Negócios Internacionais } \\
\text { abrangem a Teoria do } \\
\text { Comportamento } \\
\text { Organizacional, além da Teoria } \\
\text { Econômica, até então aceita. }\end{array}$ & $\begin{array}{l}\text { O processo de internacionalização é visto } \\
\text { como um processo evolutivo, com } \\
\text { investimentos iniciais focados em países de } \\
\text { baixa distância psíquica (proximidade } \\
\text { cultural) e somente de forma gradual em } \\
\text { mercados mais distantes. Sua aplicação é } \\
\text { mais recomendada para firmas de pequeno } \\
\text { e médio portes. } \\
\text { As Teorias de Aprendizagem e a Teoria das } \\
\text { Redes de relacionamentos (networks) são } \\
\text { consideradas evoluções naturais do } \\
\text { pensamento desta Escola. }\end{array}$ \\
\hline $\begin{array}{ll}\text { Custos } & \text { de } \\
\text { Transação } & \end{array}$ & $\begin{array}{l}\text { O. Williamson } \\
\text { E. Anderson } \\
\text { H. Gatignon } \\
\text { C.W.Hill } \\
\text { P. Hwang } \\
\text { W. C. Kim } \\
\text { A. Madhok }\end{array}$ & $\begin{array}{l}\text { Duas ideias básicas do } \\
\text { desenvolvimento do conceito de } \\
\text { transações: } \\
\text { 1.- Contratação de empresas no } \\
\text { exterior; } \\
\text { 2.- Utilização da própria estrutura } \\
\text { da empresa. } \\
\text { Os custos de transação poderiam } \\
\text { variar, dependendo do ambiente e } \\
\text { do fator humano, notadamente em } \\
\text { culturas distintas. }\end{array}$ & $\begin{array}{l}\text { O "controle" foi considerado o mais } \\
\text { importante determinante de risco e } \\
\text { retorno. } \\
\text { O conceito de capacidades organizacionais } \\
\text { também é considerado. } \\
\text { O modo de entrada em um mercado } \\
\text { depende da compatibilidade entre rotinas } \\
\text { da empresa e aquelas necessárias para o } \\
\text { sucesso no novo mercado. }\end{array}$ \\
\hline Internalização & $\begin{array}{l}\text { P. J. Buckley } \\
\text { M. Casson } \\
\text { A. M. Rugman } \\
\text { E. Fina }\end{array}$ & $\begin{array}{l}\text { Conceitua a aplicação dos custos } \\
\text { de transação aos negócios } \\
\text { internacionais, considerando o IDE } \\
\text { (investimento direto externo) } \\
\text { como modo de entrada em um } \\
\text { novo mercado, em vez de iniciar } \\
\text { com o licenciamento. }\end{array}$ & $\begin{array}{l}\text { A sequência sugerida de modos de entrada } \\
\text { num mercado passa pelos seguintes passos: } \\
\text { 1. exportação } \\
\text { 2. investimento direto } \\
\text { 3. licenciamento. }\end{array}$ \\
\hline $\begin{array}{l}\text { Paradigma } \\
\text { Eclético da } \\
\text { Produção } \\
\text { Internacional }\end{array}$ & J. H. Dunning & $\begin{array}{l}\text { Procura explicar a amplitude, } \\
\text { forma e padrão da produção } \\
\text { internacional, com base em três } \\
\text { grupos de vantagens: } \\
\text { 1.grupo de vantagens específicas } \\
\text { da propriedade (VP); } \\
\text { 2.grupo de vantagens da } \\
\text { internalização (VI); } \\
\text { 3.grupo das vantagens locacionais } \\
\text { (VL). }\end{array}$ & $\begin{array}{l}\text { Esta teoria repousa nos três elementos PIL: } \\
\text { 1.Propriedade; } \\
\text { 2. Internalização; } \\
\text { 3.Localização, que seriam fundamentais nas } \\
\text { decisões de uma empresa em mercados } \\
\text { externos com produção no exterior. } \\
\text { Este paradigma seria mais adequado às } \\
\text { EMNs - Empresas Multinacionais. } \\
\text { Teria por objetivo, ainda, explicar as } \\
\text { operações da empresa no exterior, com } \\
\text { base em fatores exploratórios relevantes, } \\
\text { enfocando a forma e o padrão da produção } \\
\text { internacional. }\end{array}$ \\
\hline
\end{tabular}


Quadro 1 - Resumo das Teorias de Internacionalização

\begin{tabular}{|l|l|l|l|}
\hline TEORIAS & AUTORES & CONTEÚDO & DESTAQUE \\
\hline Externalização & J. C. Jarillo & Baseia-se, em parte no \\
J. I. Martinez & $\begin{array}{l}\text { modelo de Uppsala, } \\
\text { entretanto, sugere uma nova } \\
\text { dimensão, a "externalização", } \\
\text { que permite distinguir as } \\
\text { formas como as empresas } \\
\text { executam suas operações } \\
\text { internacionais, a exemplo de } \\
\text { alianças estratégicas, } \\
\text { franquias, licenças e joint } \\
\text { ventures. }\end{array}$ & $\begin{array}{l}\text { internacional de pequenas e médias } \\
\text { empresas, já que isoladamente elas não } \\
\text { dispõem dos recursos necessários para } \\
\text { competir com sucesso no exterior. } \\
\text { Considerando o comportamento } \\
\text { competitivo, defendido pela Escola } \\
\text { Nórdica, esta nova dimensão viria a } \\
\end{array}$ & $\begin{array}{l}\text { complementá-lo pelo igualmente } \\
\text { importante comportamento cooperativo. }\end{array}$ \\
\hline
\end{tabular}

Fonte: Desenvolvido pelos autores com base em Rocha, (2002, p.14-59).

Em relação à internacionalização de pequenas empresas pode-se acrescentar ainda ao quadro de Rocha (2002) duas outras correntes teóricas: a do Empreendedorismo Internacional e a das Born Globals. Para Young, Dimitratos e Dana (2003), o estudo do Empreendedorismo Internacional foi influenciado pela Visão Baseada em Recursos e pela Teoria das Redes. Wennberg e Holmquist (2008) apontam que esta teoria enfoca as características do empreendedor e da empresa, de forma a entender o que leva o decisor a ter um comportamento empreendedor e buscar o mercado internacional. A Teoria das Born Globals tenta explicar como pequenas empresas se internacionalizam com poucos anos de existência (RENNIE, 1993). Acredita-se que as Born Globals já possuem conhecimento acerca do mercado internacional antes mesmo de iniciarem suas atividades em um mercado estrangeiro, tanto pela experiência do empreendedor como pelos contatos que a empresa e/ou o empreendedor possuem em outros mercados (OVIATT; MCDOUGALL, 1995).

As teorias comportamentais de internacionalização são as que melhor se aplicam às micro, pequenas e médias empresas (MPME's), pela maneira como propõe a escolha dos mercados de forma gradativa e por proximidade psíquica (ROCHA, 2002), sobretudo a partir das evoluções propostas que contemplam as redes de relacionamento (COVIELLO; MUNRO, 1997; JOHANSON; MATTSON, 1988; LU; BEAMISH, 2001; HADLEY; WILSON, 2003). Johanson e Valhne (2009) identificaram que as redes sociais podem impactar na seleção dos mercados externos, assim como nos modos de entrada. Segundo esta Teoria, o grau de internacionalização depende do número e da força dos relacionamentos. 
A pesquisa existente sobre as redes sociais tem contribuído para a compreensão de como os empresários expandem seus negócios. Estudos que utilizam uma perspectiva de redes sociais mostram que laços sociais informais dos empresários influenciam o desempenho das empresas (LU; BEAMISH, 2001) e desempenham um papel fundamental na internacionalização (JARILLO, 1988).

De acordo com Zhou, Wu e Lu (2007), as relações sociais atuam como mecanismos de mediação e proporcionam três benefícios de informação: (1) o conhecimento das oportunidades no mercado externo, (2) aconselhamento e aprendizagem experiencial, e (3) a confiança e solidariedade. Os autores sugerem que os gerentes de negócios internacionais devem considerar as redes sociais como um meio eficaz de ajudar as PME's na sua orientação internacional para acelerar o processo de internacionalização e para torná-lo mais rentável.

As incubadoras de empresas parecem ser ambientes que podem potencializar as competências necessárias para a internacionalização na medida em que favorecem as relações sociais e constituem-se como ambiente "naturalmente" inovador.

\subsection{INCUBADORAS DE BASE TECNOLÓGICA}

As incubadoras de empresas são ambientes dotados de capacidade técnica, gerencial, administrativa e infraestrutura para amparar o empreendedor (ANPROTEC, 2006). O objetivo é disponibilizar além de espaço, condições efetivas para transformar ideias inovadoras em empreendimentos de sucesso.

As incubadoras de base tecnológica (IBT's) possuem particularidades que as diferenciam das demais, tais como a intensa relação com o setor produtivo e com instituições de ensino e pesquisa; e com outros parceiros que podem auxiliar o processo de inovação (BAÊTA, 1999). Phan, Siegel e Wright (2005) corroboram com Baêta ao definirem as incubadoras como organizações focadas em acelerar negócios por intermédio da aglomeração do conhecimento e compartilhamento de recursos.

Destaca-se ainda neste contexto, a importância da inovação para o setor de base tecnológica, pois esses setores são formados por estruturas desenhadas para estimular a 
criação através de pesquisa e desenvolvimento, bem como, para gerar a consolidação de empreendimentos competitivos e inovadores (ENRÍQUEZ; COSTA, 2001).

Nesse cenário, onde o conhecimento, a eficiência e a rapidez no processo de inovação passam a ser reconhecidamente os elementos decisivos para a competitividade das economias, o processo de incubação pode ser crucial para que a inovação se concretize em tempo hábil para suprir as demandas do mercado (BRASIL, 2000; BALDISSERA, 2001).

Dornelas (2006) ressalta também que a incubadora pode prover contatos com empresas âncoras e capitalistas interessados em investir em novas empresas, atuando como um passaporte para o mercado exterior (DORNELAS, 2002). Cortezia e Souza (2011), em análise sobre o processo de internacionalização de pequenas empresas do setor de software, identificaram que as redes promovidas pelas incubadoras foram fundamentais para a internacionalização, além de mencionarem ações concretas da incubadora como a organização de missões técnicas para o exterior, destacado por várias empresas como ponto de início das atividades internacionais. Santa Rita e Baeta (2005) destacam que o apoio à internacionalização de empresas deve fazer parte da missão das incubadoras, uma vez que o desenvolvimento econômico neste cenário globalizado passa por transações internacionais. Lahorgue (2004) em pesquisa realizada em 2004 identificou que algumas incubadoras brasileiras ofertavam serviços específicos de apoio à exportação.

Jabour, Dias e Fonseca (2004) acrescentam que as incubadoras são locais propícios para a geração de redes empresariais em favor da inovação e da partilha de conhecimentos (LASTRES; CASSIOLATO, 2003). Assim, as incubadoras, mecanismos formadores de redes e promotoras da inovação, constituem-se em uma oportunidade única de aprendizagem compartilhada (LUNDVALL, 1992; KANTER; KAO; WIERSEMA, 1998). Lundvall (1992) defende que as inovações dependem de um sistema de Inovação estruturado que permita interações, ou seja, formação de redes, entre o empreendedor com os demais atores do sistema, nesse sentido a incubadora configura-se como uma instituição mediadora.

E nesse contexto, enquanto instituições que estimulam as redes sociais e por consequência a inovação, as incubadoras podem também desempenhar importantes papéis na identificação de novas oportunidades, na facilitação de acesso a mercados 
externos e desenvolvimento de vantagens competitivas específicas por meio do acúmulo de conhecimento sobre o mercado internacional e o estabelecimento de ligações formais entre negócios no processo de internacionalização.

Por outro lado, pesquisas apontam que apesar de reconhecerem sua importância, as incubadoras brasileiras não apresentaram uma preocupação efetiva com o processo de internacionalização das empresas incubadas (BAÊTA; BORGES; TREMBLAY, 2005; SANTA RITA; BAÊTA, 2005). O que aponta para uma necessidade de maior aprofundamento do papel das incubadoras neste processo de internacionalização, inclusive para tentar identificar os motivos que tem dificultado uma ação mais ativa nesta direção.

\section{METODOLOGIA DA PESQUISA}

A abordagem do problema foi Qualitativa visando descrever a complexidade dos processos de internacionalização das empresas estudadas, analisando a interação de certas variáveis. Quanto aos objetivos da pesquisa, pode-se classificá-la como Descritiva, pois descreve o processo de internacionalização e, como Explicativa, pois identifica as motivações e fatores determinantes do processo de internacionalização e o papel da incubadora neste contexto (ANDRADE, 2002).

Quanto à estratégia da pesquisa optou-se por um estudo de múltiplos casos, pois permite compreender o fenômeno de maneira mais ampla, ao comparar empresas semelhantes, mas, com peculiaridades únicas (YIN, 2001). Foram selecionadas seis empresas de maneira intencional, de forma a compor um grupo para estudo que tivesse determinadas características de interesse do grupo, quais sejam: ser pequena ou média empresa, ser empresa de base tecnológica (EBT), ter desenvolvido ou estar desenvolvendo atividades de internacionalização e, finalmente, ser uma empresa incubada ou graduada. Ao definir estas condições de contorno, realizou-se contato com empresas da região metropolitana de Florianópolis buscando a adesão voluntária dos gestores. A partir dos contatos realizados e das manifestações de participação voluntária, a amostra foi composta de seis empresas sendo três incubadas e três graduadas. Ressalta-se ainda que duas incubadas e duas 
graduadas são oriundas de uma incubadora, enquanto as demais são originárias de outra, ambas localizadas na mesma cidade. 0 quadro 2 apresenta suas características:

Quadro 2 - Caracterização das empresas pesquisadas

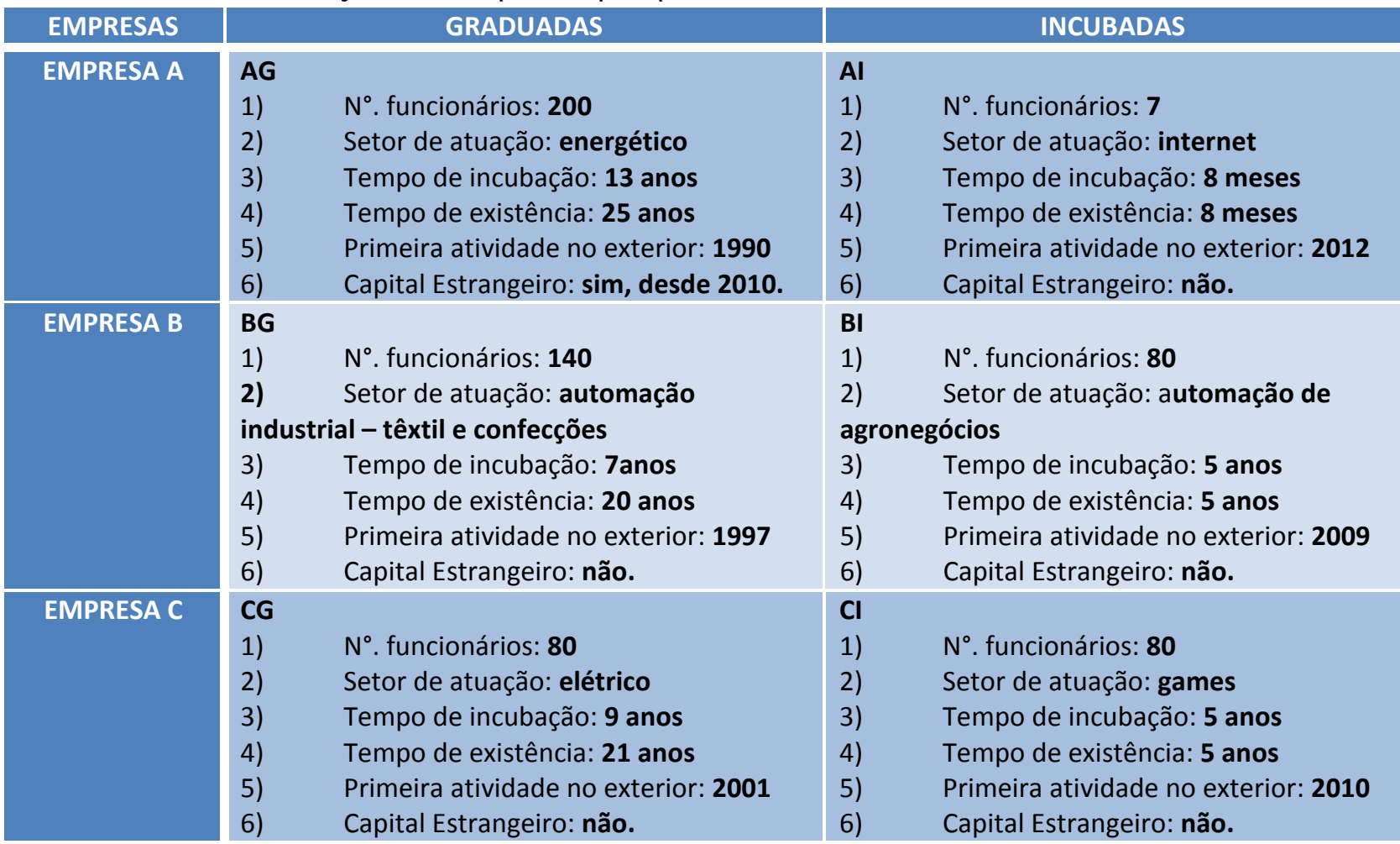

Fonte: Elaborado pelos autores, (2012).

As três empresas graduadas já são maduras, inclusive no mercado internacional, onde atuam há mais de dez anos. Uma delas possui, atualmente, capital estrangeiro investido na empresa. As empresas incubadas, porém, são mais jovens e sua ação internacional ainda é incipiente.

Os dados foram coletados por meio de entrevistas semiestruturadas com questões abertas e fechadas, tanto com os gestores das empresas e como com os gestores das incubadoras. Em alguns casos os entrevistados foram convidados não apenas a apontar qualitativamente alguns aspectos, mas também a classificá-los por ordem de importância, o que permitiu nestes casos uma análise mista. Por exemplo, ao questioná-los acerca dos motivos que os levaram a buscar mercados internacionais, foi solicitado adicionalmente que os motivos apresentados fossem ordenados por importância para a empresa. Além das variáveis de controle apresentadas no quadro 2, buscou-se conhecer ainda o R. eletr. estrat. neg., Florianópolis, v.6, n.1, p. 252-274, jan./abr. 2013 
comportamento das seguintes variáveis: mercados procurados; motivação para estes mercados; existência de instalações próprias no exterior; modalidade de entrada; motivações para a internacionalização de atividades; vantagens competitivas necessárias para a entrada em mercados internacionais; dificuldades para internacionalizar; desempenho com atividades internacionais; papel formal e informal das incubadoras no processo de internacionalização; e, fatores que influenciam o papel da incubadora.

A análise dos dados foi realizada a partir da análise de narrativa, as empresas, sempre que possível, são identificadas na análise pelas iniciais ( $A G, B G, C G, A l, B I$ e $C l$ conforme caracterizadas no quadro 2 .

\section{APRESENTAÇÃO E ANÁLISE DOS DADOS}

As primeiras observações referem-se à idade das empresas quando de sua primeira inserção internacional. A empresa mais jovem iniciou o processo com meses de existência, podendo se configurar como uma Born Global (OVIATT; MCDOUGALL, 1995) ou mesmo uma empreendedora internacional acelerada (YOUNG; DIMITRATOS; DANA, 2003) enquanto a empresa que iniciou suas atividades internacionais mais tarde o fez com 11 anos. Esta foi a única empresa que iniciou o processo após já ter saído da incubadora.

Quanto aos mercados procurados, percebe-se que as graduadas buscaram países do MERCOSUL para iniciar a internacionalização, mostrando uma aderência com a escola de Uppsala buscando países com maior proximidade psíquica para, posteriormente, com a aprendizagem e o amadurecimento, aventurarem-se em novos destinos. Atualmente, as três graduadas atuam, além da América do Sul e Central, na América do Norte e União Europeia, duas delas atuam também na África e uma atua na Ásia, Leste Europeu e Rússia. Entre as incubadas, o movimento foi diferente, já que uma delas nem atua no MERCOSUL, e duas delas iniciaram suas atividades internacionais na América do Norte. Todas atuam na União Europeia, sendo que uma delas ampliou sua atuação para o Leste Europeu e Rússia.

Todas as graduadas possuem escritórios no exterior para comercialização de seus produtos ou serviços, mas com estruturas pequenas (1 a 4 funcionários). Uma delas (BG) destacou que, com a crise europeia, um dos escritórios sediado na Europa, foi 
desativado há dois anos. Entre as incubadas, duas delas ( $\mathrm{BI}$ e $\mathrm{Cl}$ ) possuem sede no exterior, porém também bastante enxutas e voltadas à comercialização e suporte dos produtos, uma com dois e outra com cinco funcionários.

Quanto às modalidades de entrada no mercado externo, duas das graduadas começaram a exportação de produtos a partir da sede brasileira, enquanto a terceira iniciou a exportação a partir de um escritório de vendas no exterior (BG). Uma delas, a empresa BG, após as primeiras exportações, estruturou um escritório de vendas na Europa e montou redes de distribuição nos demais mercados atendidos. Mais recentemente, a empresa iniciou algumas alianças estratégicas e adquiriu uma empresa no exterior, que representava um de seus concorrentes. A terceira empresa, AG, após o amadurecimento das exportações optou pelo Investimento Direto Externo, do tipo Greenfield, implantando uma subsidiária própria em um de seus maiores mercados e um escritório de vendas em outro. Para as graduadas, a Teoria de Uppsala que defende a internacionalização desenvolvida em estágios que evoluem a partir da aprendizagem sobre o processo e o novo mercado, possui poder explicativo.

Diferentemente, nenhuma das incubadas começou com exportação direta. Uma das empresas iniciou com uma aliança estratégica e, depois, buscou o licenciamento de produtos e marcas no exterior $(\mathrm{Cl})$. Outra empresa iniciou com uma parceria com distribuidores locais para depois começar as exportações que evoluíram para a abertura de um escritório próprio de vendas e a realização de aliança estratégica (BI). Uma delas apontou que as vendas no exterior ocorreram via comércio eletrônico, cujo crescimento proporcionou a abertura de um escritório de vendas no exterior (Al). Nestas empresas, o processo parece ser acelerado, sobretudo em uma delas, que se caracteriza como uma Born Global, o qual se aproveitou dos avanços nas tecnologias de informação e comunicação para iniciar suas ações externas. Em todas as empresas, o conhecimento desenvolvido ao longo do processo de internacionalização mostrou-se fundamental para a ampliação destas atividades, corroborando Johanson e Valhne (2009).

As motivações para a internacionalização são as mesmas para incubadas e graduadas, apenas com alterações na ordem de importância. Em ambos os casos, percebe- 
se que a visão do empreendedor é vista como mais importante do que a existência de uma demanda inesperada, concordando com os resultados de Wennberg e Holmquist (2008).

Percebe-se ainda que a busca por mercados externos nas empresas graduadas aconteceu de forma planejada, buscando a expansão de mercado por um esgotamento iminente do mercado interno. Isto ocorreu também com uma das incubadas que já possui uma fatia majoritária do mercado nacional e enxergou no mercado externo sua possibilidade de expansão (BI). Outras duas incubadas já desenvolveram seus planos de negócios e produtos vislumbrando o mercado global, embora para uma delas a internacionalização tenha demorado mais que o planejado (quatro anos - empresa $\mathrm{Cl}$ ). Ressalta-se ainda que em ambos os grupos, foi citado como motivação as experiências bem sucedidas de outras empresas que fazem parte de sua rede de relacionamento. Este fator é importante, pois, o cerne, ou nó central, desta rede é a incubadora, o que aponta que mesmo por ação indireta a incubadora potencializa a motivação para a busca de novos mercados. Fato que foi corroborado pelos entrevistados, porém apenas depois de questão complementar dos pesquisadores, como se não houvesse clareza dessa percepção a priori.

Ao serem questionados acerca das vantagens competitivas necessárias para concorrer no mercado internacional, ambos os grupos são unânimes em apontar a inovação como principal fator de diferenciação e, embora com um nível de importância bem menor, a imagem da marca da incubadora também foi relacionada como um relevante fator (LACHENMAIER; WOBMANN, 2004; ENGELM, 2010). Ressalta-se, porém, que como a incubadora pode contribuir para o desenvolvimento da inovação, ao promover aglomeração do conhecimento e compartilhamento de recursos (PHAN; SIEGEL; WRIGHT, 2005) pode-se considerar que a incubadora contribui, mesmo que indiretamente, para a internacionalização de suas empresas.

Quanto às dificuldades encontradas para internacionalização, percebe-se que ambos os grupos apontam as mesmas dificuldades seguindo a mesma ordem de importância. O principal aspecto levantado é a dificuldade de encontrar pessoas ou empresas qualificadas para dar suporte à operação internacional. Algumas empresas relatam que levar brasileiros para gerenciar as operações internacionais ocasiona uma sensação de transitoriedade destes profissionais no exterior, o que implica, em alguns casos, 
Gabriela Gonçalves Silveira Fiates - Cristina Martins - José Eduardo Azevedo Fiates - Graciella Martignago - Neri dos Santos

problemas de continuidade. Na tentativa de encontrar pessoal local, as empresas se deparam com problemas culturais e de competência técnica dado o nível de inovação dos produtos comercializados. Neste sentido, a incubadora poderia auxiliar fortalecendo redes internacionais com instituições de ensino em países de interesse.

Apesar das expectativas em relação às atividades internacionais, o desempenho dessas atividades tem ficado aquém do esperado. O faturamento resultante das atividades internacionais varia entre $3 \%$ a $20 \%$ do total faturado pela empresa no caso nas graduadas, e de $1 \%$ a $50 \%$ nas incubadas. Os empresários, com atividades há mais tempo no mercado internacional indicam os efeitos da crise econômica internacional como o principal motivo para este desempenho, um deles indica, ainda, o crescimento da indústria chinesa como um dos principais obstáculos ao crescimento no exterior.

Quanto ao papel formal da incubadora no processo de internacionalização, as três incubadas avaliam que "estar em uma incubadora" auxiliou seu ingresso no mercado internacional. No entanto, dentre as graduadas, apenas uma (BG) reconhece que a incubadora pode ter contribuído com o início de seu processo de internacionalização.

Contudo, ao serem questionadas sobre os aspectos da incubadora que mais contribuíram com o processo de internacionalização, todas apontaram inúmeros fatores, os quais podem ser observados no quadro 3 , por ordem de prioridade.

Quadro 3 - Papel da incubadora para início das atividades internacionais

\begin{tabular}{|l|l|}
\hline \multicolumn{2}{|l|}{ Nível de contribuição da incubadora para atividades internacionais } \\
\hline Incubadas & Graduadas \\
\hline $\begin{array}{l}\text { Possibilidade de formação de parcerias com Instituições de } \\
\text { ensino e laboratórios }\end{array}$ & $\begin{array}{l}\text { Possibilidade de formação de Redes de } \\
\text { relacionamento com outras empresas do setor }\end{array}$ \\
\hline $\begin{array}{l}\text { Possibilidade de formação de Redes de relacionamento } \\
\text { com outras empresas do setor }\end{array}$ & $\begin{array}{l}\text { Contato com a APEX para compreensão das } \\
\text { políticas para o setor }\end{array}$ \\
\hline Busca de financiamentos e fomentos diversos & Busca de financiamentos e fomentos diversos \\
\hline Identificação de oportunidades & Identificação de oportunidades \\
\hline Nome da Incubadora / Marca & $\begin{array}{l}\text { Possibilidade de formação de parcerias com } \\
\text { Instituições de ensino e laboratórios }\end{array}$ \\
\hline Assessoria de planejamento & Assessoria de planejamento \\
\hline Estrutura comercial & Nome da Incubadora / Marca \\
\hline Apoio Jurídico & Apoio Jurídico \\
\hline Custos Estruturais & Estrutura comercial \\
\hline $\begin{array}{l}\text { Contato com a APEX para compreensão das políticas para o o } \\
\text { setor }\end{array}$ & \\
\hline
\end{tabular}

Fonte: Elaborado pelos autores, (2012). 
Os fatores elencados apontam para a formação de relacionamentos e provisão de contatos explicitando a importância dada pelos empresários à formação de redes, seja com outras empresas, com Instituições de ensino e laboratórios, com a APEX (Agência Brasileira de Promoção de Exportações e Investimentos) ou com organismos de fomento (LASTRES; CASSIOLATO, 2003; JABOUR; DIAS; FONSECA, 2004).

Os empresários graduados citam, inclusive, que há uma experiência bem sucedida na incubadora, o Programa Soft Landing, Programa desenvolvido por uma das incubadoras que auxilia os empresários a darem os primeiros passos para uma entrada suave em novos mercados, auxiliando-os nos trâmites burocráticos com assessoria jurídica, comercial, contábil, etc. E destacam que, além da incubadora, existem outras redes que também colaboram na promoção das EBT's em mercados internacionais, como a ACATE (Associação Catarinense de Empresas de Tecnologia). A ACATE com uma amplitude muito maior que a incubadora também atua como um poderoso nó desta mesma rede, potencializando os seus resultados. As incubadas citam, também, como uma ação formal e estruturada, a criação do Escritório de Negócios Internacionais em uma das incubadoras, com objetivo de auxiliar as empresas, tanto na fase de prospecção de novos mercados, como de operacionalização das estratégias de entrada, o que mostra que gradualmente a incubadora está assumindo internamente esse papel, incorporando o suporte à internacionalização como parte de sua função natural para com os incubados. O que corrobora com Santa Rita e Baeta (2005) que destacam que o apoio à internacionalização de empresas deve ser missão formal da incubadora.

Outro aspecto que merece ser destacado é que experiências bem sucedidas de outras empresas de seu convívio acabam por inspirá-las a buscar trajetória semelhante, o que indica que as influências institucionais exercem efeitos na formulação e implementação da estratégia internacional, como já observou Lu (2002). Este convívio ocorre por estarem todas situadas em um mesmo polo tecnológico ${ }^{1}$, mas, sem dúvida, é reforçado pela

\footnotetext{
${ }^{1}$ Segundo ANPROTEC/SEBRAE (2002, p.83), um polo tecnológico compreende uma: "área de concentração industrial caracterizada pela presença dominante de pequenas e médias empresas de segmento empresarial de áreas correlatas e complementares, agrupadas por vocação natural em determinado espaço geográfico, com vínculos operacionais com instituições de ensino e pesquisa e agentes locais, num esforço organizado de consolidação e marketing de novas tecnologias".
} 
coexistência na mesma incubadora de base tecnológica (LASTRES; CASSIOLATO, 2003). Por outro lado, os empresários destacam que o convívio iniciado na incubadora extrapolou-a para o campo pessoal, muitos convivem socialmente por desenvolverem hobbies comuns ou por estreitarem laços familiares. Este estreitamento dos laços corrobora a tese de que as redes informais existentes a partir dos executivos também exercem influência em sua aprendizagem e em suas escolhas estratégicas (PODOLNY, 2001; MACULAN; VINHAS, 2002).

\section{CONSIDERAÇÕES FINAIS}

O estudo da internacionalizaçao de EBT's e o papel da incubadora neste processo é relevante do ponto de vista teórico, nao só pela carência de trabalhos acerca deste objeto (MAIS; CARVALHO; AMAL; HOFFMANN, 2010) mas, sobretudo, pela necessidade de ampliar a inserção destas empresas no mercado internacional. A partir do estudo de seis casos de EBT's, sendo três graduadas e três incubadas, pode-se observar que a inovação configurouse como a principal vantagem para a competição em mercados internacionais, o que corrobora os estudos de Lachenmaier e Wobmann (2004). As iniciativas em prol da internacionalização mostraram-se intencionais e planejadas, o que denota amadurecimento das empresas no que concerne ao desenvolvimento de estratégias para o mercado internacional. Constatou-se, ainda, a aceleração do processo de internacionalização nas empresas mais jovens, concebidas com uma visão global, o que sugere efeitos ambientais institucionais.

Esta pesquisa não corrobora os achados divulgados pelo estudo SOFTEX (2005) no que se refere ao método de entrada no mercado externo. As empresas pesquisadas não foram indicadas por clientes brasileiros globais, nem participaram de feiras de negócios ou consórcios de exportação, mas foram influenciadas pelas redes de relacionamento, que contam com atores atuantes no mercado externo, sendo estas redes promovidas direta ou indiretamente pelas incubadoras.

Além das dificuldades comumente relacionadas, como burocracia e tributação, os entrevistados ressaltaram a dificuldade de identificação de pessoas com expertise para a gestão dos negócios no exterior, sobretudo com conhecimento do produto comercializado. 
Comprova-se, portanto, que o conhecimento é fundamental para o processo de internacionalização, indicando que a Teoria do Empreendedorismo Internacional (WENNBERG; HOLMQUIST, 2008) baseada na 'resource-based view', que aproveita estrategicamente as características do empreendedor e da empresa, encontram respaldo nos dados coletados. Esta constatação aponta ainda para uma ação institucional das incubadoras em redes internacionais com instituições de ensino.

Embora apenas as empresas incubadas reconheçam as incubadoras como importantes para o processo de internacionalização, todas as empresas pesquisadas apontaram que a incubadora favorece a formação de redes e que estas favorecem a inovação e a interação com outros atores fomentando, por consequência, o processo de internacionalização. A incubadora é, portanto, um ambiente de forte influência no processo de internacionalização, reforçando o caráter explicativo das teorias evolucionárias e institucionalistas. As empresas incubadas destacaram a existência recente de um Escritório para internacionalização de empresas que fornece suporte às incubadas e empresas graduadas e o já consolidado Programa de Soft Landing. No entanto, todas concordam que não há além destes, outros mecanismos de cooperação formais, corroborando o trabalho de Cortes et al, (2005) que verificaram, que a adoção de mecanismos de cooperação é limitada, tendendo ao desenvolvimento de redes pouco densas e com ligações fracas entre os atores.

Esta pesquisa mostrou que há um amadurecimento das EBT's em relação à internacionalização, sobretudo nas empresas mais jovens que já planejam seu negócio com foco no mercado global. Porém, o retorno esperado com as atividades internacionais ainda fica, em geral, abaixo das expectativas, o que merece acompanhamento para verificar se este desempenho é decorrente de um mercado em recessão ou de competências limitadas da empresa.

Quanto às incubadoras, pode-se perceber que há uma real influência de seus serviços e das redes que ela promove no processo de internacionalização. No entanto, ainda há espaço para o desenvolvimento de mecanismos mais formais que permitam fortalecer os laços das redes e ampliar a cooperação entre os diversos atores. 


\section{ANALYSIS OF THE ROLE OF BUSINESS INCUBATOR IN INTERNATIONALIZATION OF BASIC TECHNOLOGY COMPANIES}

\section{ABSTRACT}

The technological and economic changes that occurred since the second half of the twentieth century expanded markets, reduced the limits imposed by national borders and promoted a real and indisputable globalization of trade, especially for emerging countries. In this context, Brazil is shown as a major player, along with other countries that make up the BRICS - Brazil, Russia, India, China and South Africa, a group with growing political power given the relevance of their markets. Nevertheless, Brazil's share in global trade is small compared to other emerging countries. The level of internationalization is particularly low in relation to products with higher added value, with components of technological innovation. Most of the products exported by Brazil in 2011 (65.8\%) consists of products of low and medium-low technology, $27.9 \%$ is medium-high technology and only $6.2 \%$ is high-tech (MDIC, 2012). Thus, this article proposes to analyze the characteristics of the internationalization of small and medium-sized technology-based companies, incubated and graduated in order to identify the role of incubators in the process. We started from three basic premises: that the technology-based companies are essentially innovative companies; business incubators constitute environments for potentiating networks, both between the incubated and graduated ones with external agents And finally, the third premise is that innovation is a competitive advantage that leverages the process of internationalization of companies and has proven crucial to the competitive performance of the company in foreign markets. The research from cases of small technology-based companies shows it is relevant given the need for Brazil to stimulate the insertion of foreign companies selling technologyintensive products, review passage The research is descriptive in character, in the form of a multicase study of six companies, three incubated and three graduated. The results show that innovation is actually set as the main advantage to compete in international markets. Intentional and planned, there is an acceleration of the internationalization process in young companies, designed with a global vision. It was found that the incubator favors the formation of social networks that encourage innovation and interaction with other actors 
that can foster the process of internationalization, however, no actions perceived by the entrepreneurs themselves for this purpose, which points to an opportunity to systematic action of the incubators in supporting the internationalization of companies.

Key-Words: Internationalization. Incubators. Innovation. Technology-Basis.

\section{REFERÊNCIAS}

ANPROTEC/SEBRAE. Glossário dinâmico de termos na área de Tecnópolis, Parques tecnológicos e Incubadoras de empresas. Brasília: Associação Nacional das Entidades Promotoras de Empreendimentos de Tecnologias Avançadas (ANPROTEC) e SEBRAE, 2002.

ANPROTEC. Panorama Anprotec. 2006. Disponível em: < http://www.anprotec.org.br/secaopanorama.php> Acesso em: 27 mai. 2011.

ANDRADE, M. M. Introdução à Metodologia do Trabalho Científico. 6. ed. São Paulo: Atlas, 2002.

BAÊTA, A.M.C. O desafio da criação: uma análise das incubadoras de empresas de base tecnológica. Petrópolis, RJ: Vozes, 1999.

BAÊTA, A. M.C.; BAÊTA, BORGES, C.V.; TREMBLAY, D.G. Empreendedorismo internacional nas incubadoras: perspectivas e desafios. Revista de Negócios, Blumenau,v. 10, n.2,p.72-87, 2005.

COELHO, F. J. P.; LARA, J. E. A assistência governamental como fator de estímulo à atividade exportadora em pequenas empresas brasileiras: um estudo introdutório. In: WORKSHOP DE INTERNACIONALIZAÇÃO, 3., 2003, Rio de Janeiro. Anais... Rio de Janeiro: Ed. Coppead, 2003.

CÔRTES, M. R.; PINHO, M. S.; FERNANDES, A. C.; SMOLKA, R.; BARRETTO, A. L. C. M. Cooperação em Empresas de Base Tecnológica: Uma Primeira Avaliação Baseada numa Pesquisa Abrangente. São Paulo em Perspectiva, São Paulo, v. 19, n. 1, p. 85-94, 2005.

CORTEZIA, S. L. D.; SOUZA, Y. S. de. Uma análise sobre a internacionalização de pequenas empresas brasileiras da indústria de software. Brazilian Business Review, Vitória, v. 8, n. 4, Art. 2, p. 24-45, Out-Dez. 2011.

COVIELLO, N.; MUNRO, H. Network relationships and the internationalization process of small software firms. International Business Review. 6(2), 1997, págs 1-26. 
ANÁLISE DO PAPEL DA INCUBADORA NA INTERNACIONALIZAÇÃO DE EMPRESAS DE BASE TECNOLÓGICA, INCUBADAS E GRADUADAS.

Gabriela Gonçalves Silveira Fiates - Cristina Martins - José Eduardo Azevedo Fiates - Graciella Martignago - Neri dos Santos

DORNELAS, J. C. A. Planejando Incubadoras de empresas: como desenvolver um plano de negócios para incubadoras de empresas. Rio de Janeiro: Campus, 2002.

Incubadoras promovem o empreendedorismo inovador. 2006. Disponível em: < http://www.josedornelas.com.br/artigos/incubadoras-promovem-o-empreendedorismoinovador/>. Acesso em: 15 fev. 2012.

ENGELM, R. Contribuição das Incubadoras Tecnológicas na Internacionalização das Empresas Incubadas. Dissertação de Mestrado. Porto Alegre: UFRGS, 2010.

HADLEY, R.D. AND WILSON, H.I.M. ; 'The network model of internationalization and experiential knowledge', International Business Review 12(6), 2003, págs 697-717.

JABOUR, C.; DIAS, P.; FONSECA, S. As incubadoras empresariais como redes de empresas pró-inovação. In: SIMPÓSIO DE ENGENHARIA DE PRODUÇÃO, 6., 2004. Bauru. Anais... SIMPEP (UNESP), Bauru, 2004.

JARILLO, J. On strategic network. Strategic Management Journal. Vol. 9, pp.31-41, 1998.

JOHANSON,J.;VAHLNE,J. The Uppsala internationalization process model revisited: from liability of foreignness to liability of outsidership. Journal of International Business Studies, n. 40 , p. 1411-1431.

KANTER, R.; KAO, J.; WIERSEMA, F. Pensamento inovador na 3M, DuPont, GE, Pfizer e Rubbermaid: acesso instantâneo às estratégias de ponta da atualidade. Tradução: June Camargo. São Paulo: Negócio Editora, 1998.

LAHORGUE, M. A., Parques, pólos e incubadoras: instrumentos de desenvolvimento do século XX1.Brasilia: ANPROTEC/SEBRAE,2004.256p.

LASTRES, H.M.M; CASSIOLATO, J.E. Glossário de Arranjos e Sistemas Produtivos e Inovativos Locais. 2003. Disponível em: < http://www.loures.ecn.br/td_redesist/glossario.pdf >. Acesso em: 15 fev. 2012.

LU, J. Intra and Inter-organizational Imitative Behavior: Institutional Influences on Japanese Firms Entry Mode Choice. Journal of International Business Studies, (33):19-37, 2002.

LU, J. \& BEAMISH, P. The Internationalization and Performance of SMEs. Strategic Management Journal, Vol. 22, pp.565-586, 2001.

LUNDVALL, B. A. National systems of innovation: Towards a theory of innovation and interactive learning. Pinter Publ. London, 1992. 
LACHENMAIER,S.; WOBMANN,L. Does Innovation Cause Exports? Evidence from Exogenous Innovation Impulses and Obstacles using German Micro Data. Mar., 2004. Disponível em: www.cesifo.de/link/lachenmaiers s.html. Acesso em 14 nov. 2011.

MAIS, I.; CARVALHO, L.C.; AMAL, M.; HOFFMANN, M. Gaia. Importância das redes nos processos de inovação e internacionalização de empresas de base tecnológica. Revista de Administração e Inovação, São Paulo, v. 7, n. 1, p. 41-61, jan./mar. 2010. Disponível em: < http://redalyc.uaemex.mx/redalyc/pdf/973/97317009004.pdf>. Acesso em: 25 abr. 2012. MACULAN, A. M; VINHAS, V. Reflexões sobre o desempenho inovador de empresas graduadas. XXII Simpósio de Gestão da Inovação Tecnológica. Anais... Salvador, 2002.

MARCOVITCH, V.; SANTOS, S.A.; DUTRA, I. Criação de empresas com tecnologias avançadas. Revista de Administração, São Paulo, FEA/USP, v. 21, n. 2, abr./jun. 1986.

MARKWALD, R.; PUGA, F.“Focando a Política de Promoção de Exportações". Texto para Discussão, no 160, Rio de Janeiro, Fundação Centro de Estudos do Comércio Exterior Funcex, 2002.

MDIC. Ministério do Desenvolvimento, Indústria e Comércio Exterior. Balança Comercial Brasileira - Dados Consolidados. 2012. Disponível em: < http://www.mdic.gov.br//arquivos/dwnl_1331125742.pdf >. Acesso em: 14 abr. 2012.

OVIATT, B.; MCDOUGALL, P."Global Start-Ups: Entrepreneurs on a Wold-Wide Stage", Academy of Management Executive, v. 9, n. 2, 1995. p. 30-43

PHAN, Phillip H.; SIEGEL, Donald S; WRIGHT, Mike. Science parks and incubators: observations, synthesis and future research. Journal of Business Venturing, New York, v.20, p. $165-182,2005$

ROCHA, Ângela da et al. A Internacionalização das Empresas Brasileiras: Estudos de Gestão Internacional. Rio de Janeiro: MAUAD Editora Ltda., 2002

SALONER, G.; SHEPARD, A.; PODOLNY, J.. Strategic management. New York, Wiley, 2001.

SANTA RITA, E; BAETA, A.M.C. Desenvolvimento regional e empreendedorismo internacional: como atuam as incubadoras no Brasil? Gestão \& Tecnologia .v. 5, n. 2, 2005: referente ao v.6, n.1, jul./dez. 2005.

SANTOS, M. I. B. Os determinantes das Exportações das Empresas do Distrito de Aveiro. 2011. 116f. Relatório de Estágio (Mestrado em Economia)- Universidade de Aveiro, Aveiro, 2011.

SUZIGAN,W.; FURTADO, J. Instituições e Políticas Industriais e Tecnológicas: Reflexões a partir da experiência brasileira. Estudos Econômicos, v.40, n.1, p.7-41, jan-mar., 2010. 
ANÁLISE DO PAPEL DA INCUBADORA NA INTERNACIONALIZAÇÃO DE EMPRESAS DE BASE TECNOLÓGICA, INCUBADAS E GRADUADAS.

Gabriela Gonçalves Silveira Fiates - Cristina Martins - José Eduardo Azevedo Fiates - Graciella Martignago - Neri dos Santos

VEIGA, P. e MARKWALD, R. Pequenas e médias empresas nas exportações. In REIS RENNIE, M. Born Global. McKinsey Quarterly, 4, 25-52, 1993.

SOFTEX. Perfil das empresas exportadoras de software. Campinas, 2005.

SCHUMPETER, J. The Theory of economic development. Cambridge, Mass: Harvard University Press, 1934.

WENNBERG, K.; HOLMQUIST, C. Problemistic search and international entrepreneurship. European Management Journal, 26, 441-454, 2008.

YOUNG, S.; DIMITRATOS, P.; DANA, L. International entrepreneurship research: what scope for international business theories. Journal of Intl Entrepreuneurship, 1, 31-42, 2003.

YIN, R. K. Estudo de caso - planejamento e métodos. 2 Ed.Porto Alegre: Bookman, 2001.

ZHOU, L.; WU, W.; LUO, X. Internationalization and the performance of born-global SMEs: the mediating role of social networks. Journal of International Business Studies, 38, 2007, págs 673-690. 